\title{
Stripping process modelling: interaction between a moving waterjet and coated target
}

\author{
Tarek Mabrouki *, Kadour Raissi \\ LMSP-UMR CNRS-ENSAM-ESEM, Ecole Nationale Supérieure d'Arts et Métiers (ENSAM-Paris), 151, Bd de l'Hôpital 75013 Paris, France
}

\begin{abstract}
This paper deals with the numerical modelling of stripping process by a mono-jet moving tool. The example of aeronautic coating (polyurethane) deposit on an infinite homogenous metal (A2024) was treated.

The numerical computation was carried out using Dyna3D code. In order to study the jet-target interaction, we have used an eulerian description for the fluid (waterjet+air) and a lagrangian formulation for the target. The interaction between the two meshes is based on euler-lagrange coupling. The Hydrodynamic results show the importance of the jet flattening on the treated-coated target. It appears clearly that moving watertjet introduces, during decoating process, shear stresses causing coating removal by erosion mode. The latter has been simulated thanks to a failure criterion of lagrangian elements illustrating the coating removal under high velocity moving waterjet. This erosion is accentuated by waterjet stretching effects, which cause tearing of the coating. Consequently, discontinuous cracks at the median line of the coating imprint can be observed. These cracks can be privileged sites, which are traversed by speedy micro-jets accelerating the coating removal. Our results were demonstrated by experimental tests.
\end{abstract}

Keywords: Waterjet; Stripping; Modelling; Decoating; Erosion

\section{Introduction}

The surface preparation industry needs new technologies to replace existing decoating processes. Indeed, current methods are either too costly or becoming restricted by environmental rules. One example of conventional stripping is by a chemical process, which is becoming unpopular because of the harmful action of the volatile organic components. Moreover, abrasive blasting, such as grit and sand blasting, may soon be prohibited for use because of environmental issues related to their release into the air or water and disposal of the heavy metals used (e.g. marine coatings: copper, cadmium and lead).

Among the new technologies, which seem to be capable of solving the current stripping problems, is the waterjet technology process, which has been used for a long time for cleaning (e.g. gas turbine, engine parts) and cut-

\footnotetext{
* Corresponding author. Fax: +33-1-442-246-224.

E-mail address: mabrouki@paris.ensam.fr (T. Mabrouki).
}

ting (metals, plastic, concrete). Recently, aeronautical and naval sectors have used this process to strip reactors and craft coke. Many operations, such as cleaning, decoking, decoating of technical deposits (like thermal spray coatings), are particularly specified by designers to be carried out by HP waterjets. Although the appreciable development of a new coating-removal system (tool and automation), the waterjet stripping process is still facing many problems. An example of these problems can be seen when using a rotary stripping head (Fig. 1a). Indeed, in many cases the latter can generate, on the piece treated, a bad surface quality and layer selectivity.

In order to improve the waterjet stripping process, many authors have published papers concerning the interaction of the jet with the target. Various quality criteria were investigated and modelled. However, notwithstanding the amount of papers concerning cleaning applications by means of experimental studies [1-4], we can find very few papers dealing with decoating theory and simulation [5-7]. Some phenomena, which are involved in the interaction of the waterjet and the target, are still as yet insufficiently explained. In this optic, Leu 


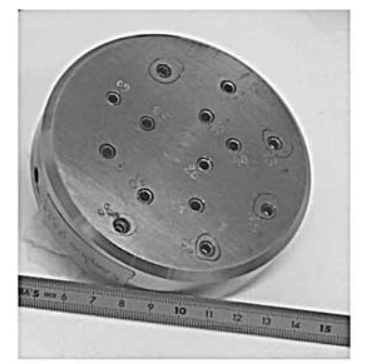

(a)
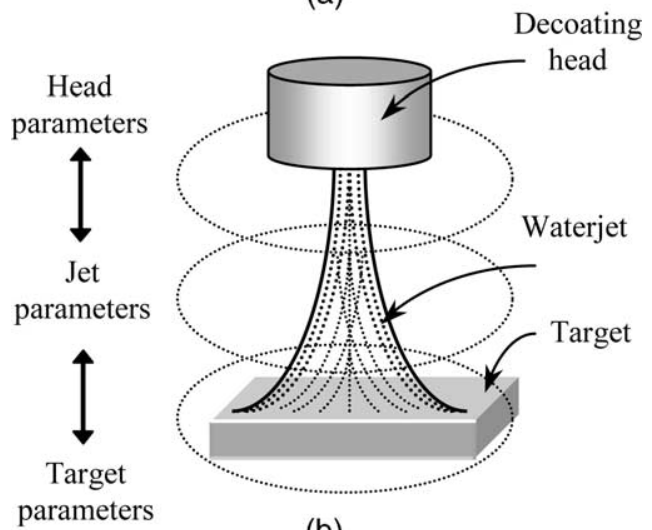

(b)
Fig. 1. Industrial rotary multijet decoating head.

et al. [5] and Meng et al. [6] have developed two mathematical models for cleaning using stationary and moving waterjets. The models are established by applying the theoretical structure of the waterjet in air and by considering that cleaning occurs when the equivalent dynamic stress due to the water droplets is greater or equal to the endurance limit of the coating material [8]. In these papers, the authors do not consider the evolution of the cleaning according to time. They assume that the equivalent dynamic stress is the only criterion for total decoating. In addition the coating/substrate interface and substrate characteristics were not taken into account in the formulation of the model. Their analytical study is focused on the influence of the work parameters on the cleaning width. Recently, Louis et al. [7] have presented a modelling approach of a decoating process of an epoxy-resin coated steel plate. In order to describe work piece fatigue, the authors have based their model on linear accumulation of single droplet damage. The coating erosion is approximated by a function of the masses and velocities of the impinging droplets.

Within this framework, the present paper focuses on studying the mechanics of the coating removal process by HP pure waterjet. We point out that we have started presenting this study in previous papers with the comprehension of coating erosion mode by continuous water jet impact [8]. However, since the stripping process by the rotary head is carried out at stationary phase by means of the moving waterjet, it is important to study this case of waterjet coating removal. Therefore, we have studied the main phenomena occurring when there is relative movement between the waterjet and the coated target. For that, we have adopted a finite element numerical method [10]. Numerical erosion was introduced in order to simulate real erosion. For our model validation, we have performed various experiments.

\section{Problem formulation}

A decoating operation using a pure HP waterjet consists in removing, from a substrate, a material unusable (in the case of cleaning) or damaged, in order to carry out an operation of restoration. Logically, the stripping operation must be carried out without attacking or changing the integrity of the substrate. This vision leads us to present the most important parameters influencing the decoating process. They can be divided into three types (Fig. 1b).

- Head parameters: they include head geometry, work pressure, water rate flow.

- Jet parameters: they are related to jet formation in the air [water and air phases, jet kinetic evolution, standoff distance, physical properties (density, viscosity, etc)].

- Target parameters: they include intrinsic mechanical characteristics as well as the physicochemical properties of the materials (coating+substrate).

These various parameters interact and constitute a big set, which is difficult to manage. In industrial decoating cases many jets are delivered by a rotary multijet head (Fig. 1a). The latter tool has several cylindrical nozzles, which are implemented intelligently to provide an uniform kinetic energy distribution of jets. With this type of stripping head, the coating removal operation is released by composing the rotational movement of the head with its traverse speed. Consequently, the coating is marked by cycloid imprints representing the jet impacts (Fig. 2).

Table 1 presents some operating parameter values for the multi-nozzle rotary head, used in industry.

In this modelling problem we intend to strip a polyurethane coated plate (aluminium alloy: A2024) with a moving HP pure waterjet which has a velocity of 500 $\mathrm{m} / \mathrm{s}$. The sheet has a thickness of $1 \mathrm{~mm}$ and is assumed to be infinite. This value of jet velocity is one example of velocities used in jet-stripping applications (200-900 $\mathrm{m} / \mathrm{s}$ ). In other words, we intend to simulate the case of decoating by a monojet head. For commodity and simplification many hypotheses are adopted. Indeed, we treat only the action of the waterjet core zone on coated material (Fig. 3). By referring to papers published by Yanaida [11], Neusen et al. [12] and Tikhomirov et al. 


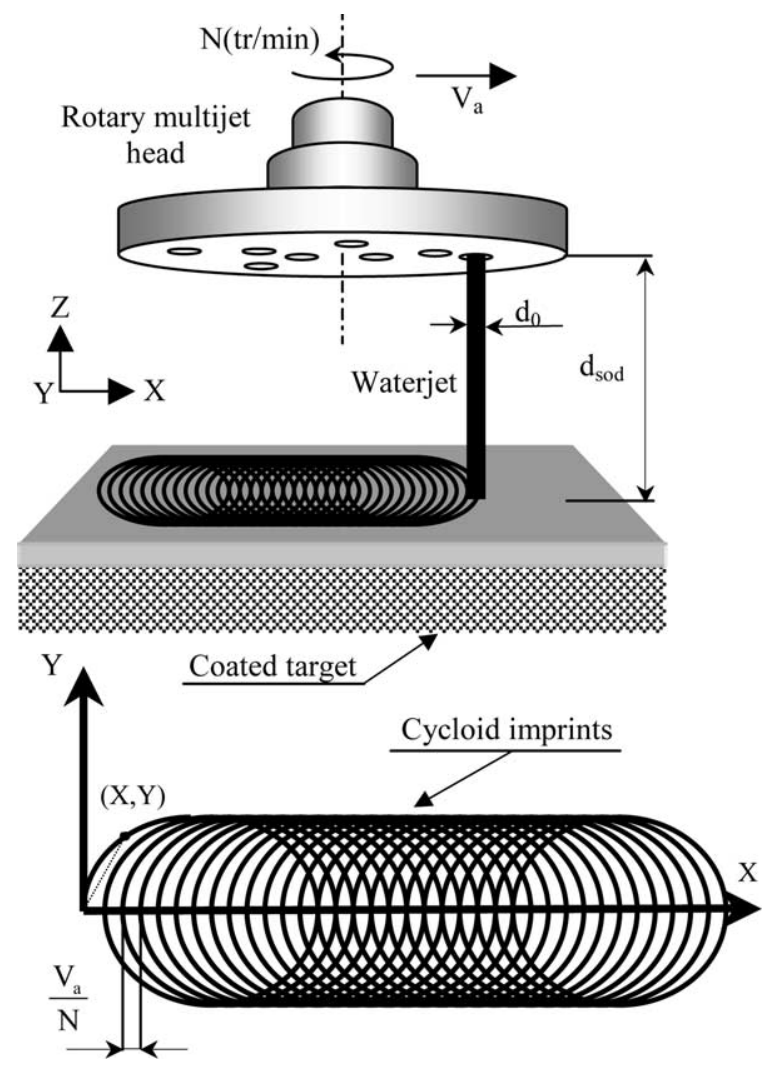

Fig. 2. Schematic representation of the waterjet action delivered by a decoating monojet head on coated target.

[13], we note that the adimensional length $\frac{x_{\mathrm{c}}}{d_{0}}$ of the core zone corresponding to an uniform velocity and monophase constituent (water) is approximately $\frac{x_{\mathrm{c}}}{d_{0}} \in[20,150]$, (Fig. 3). Consequently, for a nozzle diameter $d_{0}=0.3 \mathrm{~mm}$ and a stand-off distance $d_{\text {sod }}=30 \mathrm{~mm}$, we can assume that the waterjet is coherent and is characterised by an uniform velocity which is proportional to that of the nozzle exit (Fig. 4).

Numerically, in order to minimise the computation time (CPU), the domain of the jet flow is fixed to a value of $0.5 \mathrm{~mm}$ from the target (Fig. 5). The waterjet inlet velocity introduced in the computation is approximated to $500 \mathrm{~m} / \mathrm{s}$.

Moreover, we suppose that the following inequality is satisfied:

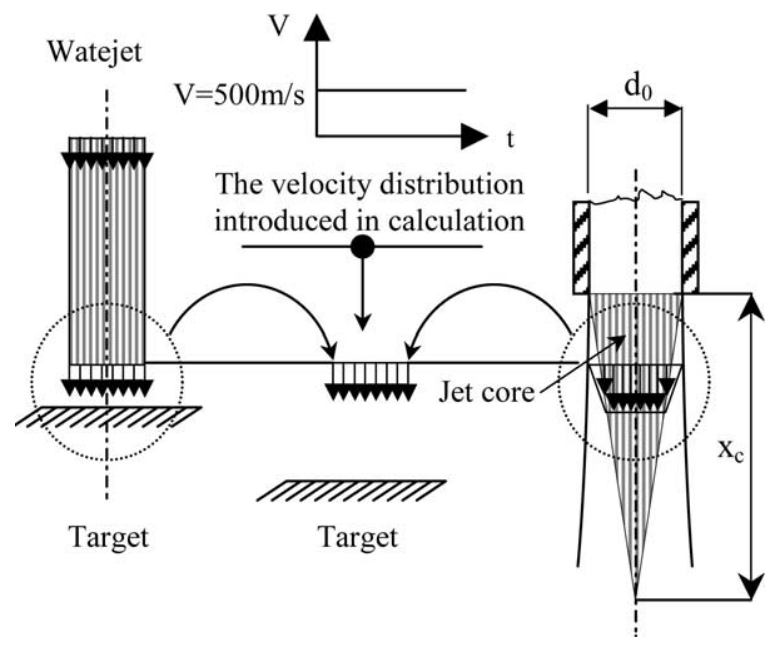

Fig. 3. (a) Cylindrical shaped jet: numerical case. (b) Structure of high-speed jet: real case. (c) Velocity introduced in our computation.

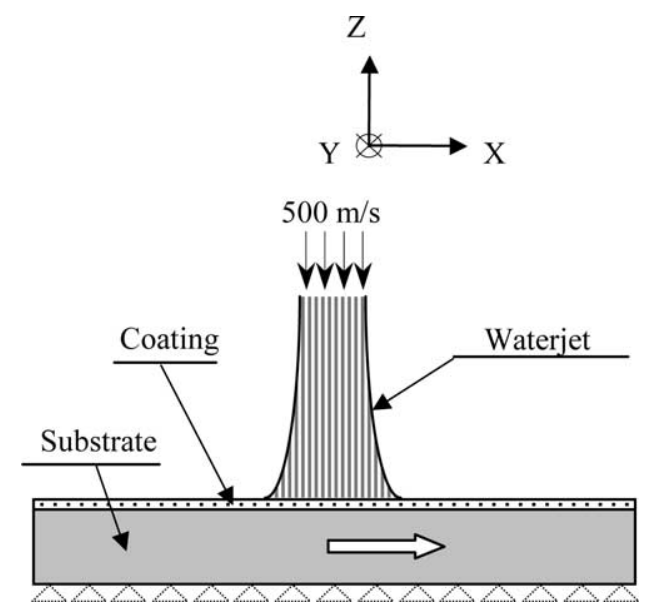

Fig. 4. Schematic waterjet decoating problem on coated material.

$\frac{V_{\mathrm{a}}}{N}<d_{0}$

This will neglect the effect of the traverse speed $V_{\mathrm{a}}$ of the decoating head when compared to its rotational linear velocity (Fig. 2) (derived from the rotation speed $N$ and the position of the jet nozzle from rotation axis).

So, the configuration corresponding to our model is the simulation of a moving waterjet (rotation) stripping a coated target. In order to represent this interaction, it is easier, from a numerical point of view, to give motion

Table 1

Operating parameters (industry)

\begin{tabular}{|c|c|c|c|c|c|c|}
\hline $\begin{array}{l}\text { Work pressure } \\
P \\
\text { (bars) }\end{array}$ & $\begin{array}{l}\text { Nozzle diameter } \\
d_{0} \\
(\mathrm{~mm})\end{array}$ & Nozzle number & $\begin{array}{l}\text { Rotation speed } \\
N \\
\text { (tr/min) }\end{array}$ & $\begin{array}{l}\text { Stand-off distance } \\
d_{\text {sod }} \\
(\mathrm{mm})\end{array}$ & $\begin{array}{l}\text { Traverse speed } \\
\mathrm{V}_{\mathrm{a}}(\mathrm{mm} / \mathrm{min})\end{array}$ & $\begin{array}{l}\text { Attack angle } \\
{ }^{\circ}(\mathrm{deg})\end{array}$ \\
\hline $\begin{array}{l}\text { Maxi. } \\
3850\end{array}$ & $0.05-0.5$ & $\begin{array}{l}\text { Maxi. } \\
13\end{array}$ & $40-1500$ & Sup. to 12 & $50-8000$ & $0-45$ \\
\hline
\end{tabular}



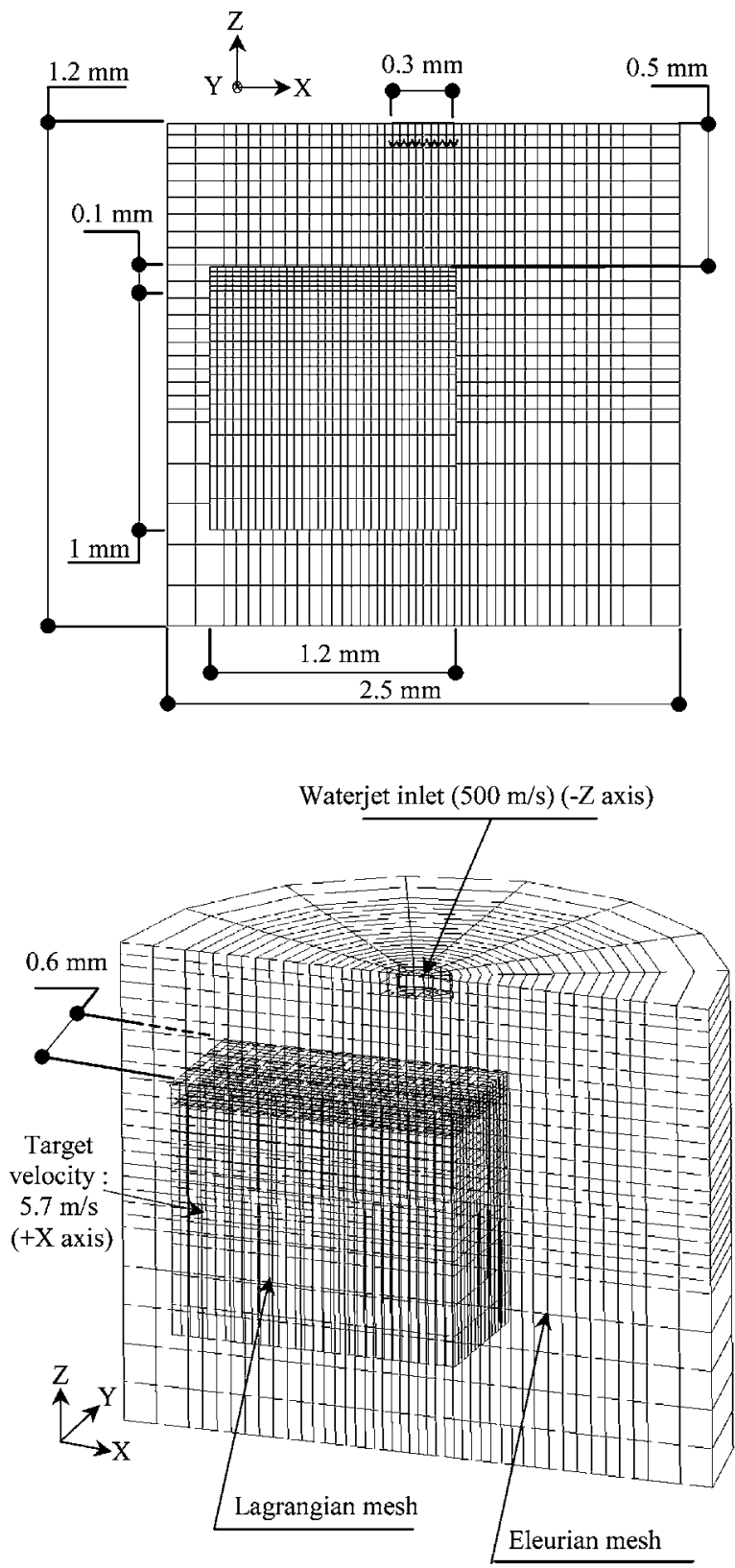

Fig. 5. Model: the lagrangian mesh (target) is embedded in the eulerian mesh (water+air).

to the target than to jet source (Fig. 4 and Fig. 5). This idea will be more clearly explained in the next section.

\section{Numerical simulation}

\subsection{Simulation by Dyna3D code}

The modelling of the jet/target interaction was carried out by Dyna3D code [10]. This code is a finite element program used to analyse the non-linear dynamic response of two- and three-dimensional structures [9]. It is based on an explicit time integration algorithm and on a lagrangian formulation of movement. Moreover, an eulerian formulation is available in Dyna3D. It is a particular case of the well-known arbitrary lagrangian-eulerian description (ALE) [14]. Both are obtained by adding convection terms to the lagrangian formulation of movement. These methods are useful to bypass distortions in lagrangian description and support high levels of compression or expansion. The relation between a mesh property and a material property are given by the following equation:

$\left.\frac{\partial f}{\partial t}\right|_{X}=\left.\frac{\partial f}{\partial t}\right|_{\eta}+c_{\mathrm{i}} \frac{\partial f}{\partial x_{\mathrm{i}}}$

Where $f$ is any physical property, $x$ are the eulerian coordinates, $X$ are the lagrangian coordinates, $\eta$ are referential coordinates and $c$ is the so-called convective velocity, which is the difference between the material velocity and the mesh one:

$c_{\mathrm{i}}=\left.\frac{\partial \mathrm{x}_{\mathrm{i}}}{\partial t}\right|_{X}-\left.\frac{\partial x_{\mathrm{i}}}{\partial t}\right|_{\eta}$.

The eulerian description can be used with the lagrangian description by means of coupling algorithms to handle the fluid/structure interaction. It is necessary to indicate that this code does not contain a turbulent fluid model to compute turbulent fluid problems. The study is developed by means of solid mechanics equations and fluid models as is showed next. In our computation, the finite element mesh used consisted of usual eight-node brick elements.

\subsection{Modelling method}

We note that the conventional lagrangian formulation will always remain the default displacement integration method in Dyna3D [10,15]. An operator-split technique is used to solve eulerian and arbitrary lagrangian-eulerian problems. The overall flow of an eulerian computation time step is carried out through two stages. The first stage is inherent to a lagrangian time step. During this phase, the mesh stores an amount of momentum and energy. Stresses, internal energy and nodal forces are computed for each element. Boundary and loading conditions are applied as in conventional lagrangian computation. In addition, several lagrangian cycles can be performed: the mesh and the matter stick together.

The second stage corresponds to an eulerian time step. The mesh is brought back to its initial position in the overall lagrangian reference system. The matter is relaxed from the mesh grid. This total relaxation of the mesh deformation is only partial in ALE calculations. The conservative variables, mass, momentum, energy and nodal velocities, are transported. The matter passes through the mesh grid: this is the advection step. 
Table 2

Values of the fluid region properties used in the computation

\begin{tabular}{llll}
\hline Fluid & $\begin{array}{l}\text { Density }(\rho) \\
\left(\mathrm{Kg} / \mathrm{m}^{3}\right)\end{array}$ & $\begin{array}{l}\text { Cut-off } \\
\text { pressure }(P c) \\
(\mathrm{Pa})\end{array}$ & $\begin{array}{l}\text { Dynamic viscosity }(\mu) \\
\left(\text { At } 20^{\circ} \mathrm{C} \text { and atmospheric }\right. \\
\text { pressure })(\mathrm{Pa} . \mathrm{s})\end{array}$ \\
\hline Water & 1000 & $-10^{5}$ & $10^{-3}$ \\
Air & 1.29 & -10 & $1.67 \times 10^{-5}$ \\
\hline
\end{tabular}

The advection method used in this simulation is based on the Donor cell scheme associated to the HIS (Half Index Shift) algorithm corrected at the first order [15]. In this method of advection, the momentum is directly computed and advected through nodes. Moreover, it is important to note that lagrangian mesh has to be embedded in the eulerian one [14].

\subsection{Material models}

\subsubsection{Fluid models (waterjet+air)}

The material models that are available for eulerian calculation are isotropic. We have chosen a hydrodynamic behaviour law for waterjet and air. This model is called Null-Material because the active part of the behaviour is the volumetric one. It is widely used in lagrangian calculations for fluids and gases; it is characterised by a dynamic viscosity $\mu$ and a pressure cut-off $P c$ (Table 2).

Furthermore, to the hydrodynamic behaviour law, we associate an equation of state, which defines the relationship between pressure, density and internal energy [Eq. (4)]. For our computation, we have introduced the following linear polynomial equation of state for each fluid (water, air):

$$
\begin{aligned}
p & =K_{0}+K_{1} \alpha+K_{2} \alpha^{2}+K_{3} \alpha^{3}+\left(K_{4}+K_{5} \alpha\right. \\
& \left.+K_{6} \alpha^{2}\right) e
\end{aligned}
$$

where: $p$ is the pressure, $e$ is the internal energy per initial volume. The coefficients: $K_{0}, K_{1}, K_{2}, K_{3}, K_{4}, K_{5}$ and $K_{6}$ are user defined constants (Table 3 ) and $\alpha$ is a function of the relative volume $V$ :

$\alpha=\frac{1}{V}-1$.

\subsubsection{Target model (coating/substrate)}

The impacted material (coating/substrate) is considered to be an elastic-plastic material. The input

Table 3

The $K_{(\mathrm{i}=1 \ldots 6)}$ are user defined constants

\begin{tabular}{llllllll}
\hline & $K_{0}$ & $K_{1}$ & $K_{2}$ & $K_{3}$ & $K_{4}$ & $K_{5}$ & $K_{6}$ \\
\hline Water & 0 & 2.2 & 9.54 & 14.57 & 0.28 & 0.28 & 0 \\
Air & 0 & 0 & 0 & 0 & 0.401 & 0.401 & 0 \\
\hline
\end{tabular}

characteristics concern the material density $\rho$, Young modulus $E$, Poisson ratio $v$ and Yield stress $R_{\mathrm{y}}$ (Table 4 ).

\subsection{Boundary conditions}

There are two types of boundary conditions. The first type concerns the eulerian grid mesh. In this case, automatic free boundaries are defined on the whole grid. Also a water inlet condition characterised by a dynamic velocity distribution $(500 \mathrm{~m} / \mathrm{s})$ is introduced at the upper part of the grid mesh (Fig. 5). Furthermore, to reduce the CPU time, a symmetry plane is defined in order to process the half model.

The second type deals with lagrangian boundary conditions. In this case, non-reflecting conditions are adopted at the boundary of the model. This will eliminate the reflection of the stress waves. The model is thus considered to be infinite. In the lower part of the target lagrangian mesh, the node translations along the $z$-axis are prohibited. The target (lagrangian mesh) is animated by a linear velocity equal to $5.7 \mathrm{~m} / \mathrm{s}$ when exposed to the waterjet.

\subsection{Euler-Lagrange coupling}

In our computation we have used an eulerian description for the fluid (jet+air) and a lagrangian formulation for the target. The interaction between the two meshes is based on euler-lagrange coupling.

The LSDYNA eulerian/lagrangian coupling is based on momentum conservation. Hence, the lagrangian structure has the ability to move through the eulerian grid. Coupling is done by constrained methods defined between special points of the lagrangian structure (named slave group) and eulerian nodes (master group). In order to allow interaction between the two meshes, the lagrangian mesh has to be embedded in the eulerian one.

We underline, also, that we have simulated the target erosion by a numerical method which involves the failure of lagrangian elements; it is called the failure strain for eroding elements [10]. It consists in introducing a threshold strain after which lagrangian elements can be removed.

The finite element mesh used consisted of usual eightnode brick elements. The total number of elements and nodes is 15464 and 21 996, respectively.

Table 4

Values of the target properties used in the computation

\begin{tabular}{lllll}
\hline Materials & $\rho\left(\mathrm{Kg} / \mathrm{m}^{3}\right)$ & $E(\mathrm{GPa})$ & $v$ & $R_{\mathrm{y}}(\mathrm{MPa})$ \\
\hline A2024 & 2700 & 73 & 0.33 & 345 \\
Polyurethane & 1200 & 0.9 & 0.25 & 40 \\
\hline
\end{tabular}




\section{Results and discussion}

In this section, we present the numerical results related to the action of the liquid-jet on an infinite homogenous metal (A2024, 1-mm width, elastic-plastic behaviour) plate coated with a $100 \mu \mathrm{m}$ polyurethane layer. This target has an elastic-plastic behaviour and is moving at $5.7 \mathrm{~m} / \mathrm{s}$ velocity. The interface between the two materials is assumed to be perfect.

\subsection{Hydrodynamic behaviour during decoating}

The waterjet inlet position is chosen $0.5 \mathrm{~mm}$ away from the moving target (minimising the time of computation). The waterjet, whose diameter is $0.3 \mathrm{~mm}$, has a velocity of $500 \mathrm{~m} / \mathrm{s}$. The coated target has a traverse speed of $5.7 \mathrm{~m} / \mathrm{s}$.

In the following, we present the hydrodynamic behaviour of eulerian constituents (fluid: water+air). Thus, we have computed the evolution of fluid total velocity during the decoating operation.

The time needed for the jet to reach the target is almost $1 \mu$ s. During this period the jet keeps its cylindrical shape. Next, the jet strikes the coated target and causes a chock state, which is characterised by instabilities occurring for $0.02 \mu \mathrm{s}$ (after impact instant) [10]. For a time corresponding to $2 \mu$ s we observe clearly the reflection of the jet (Fig. 6). During this period, the coating undergoes a deformation state at the level of the coating-jet interface. The jet reflection of the jet back region introduces boundary effects on the target, as we will observe later. Moreover, the eulerian zone (water and air) becomes more animated. For higher exposure times, the erosion phenomenon appears progressively

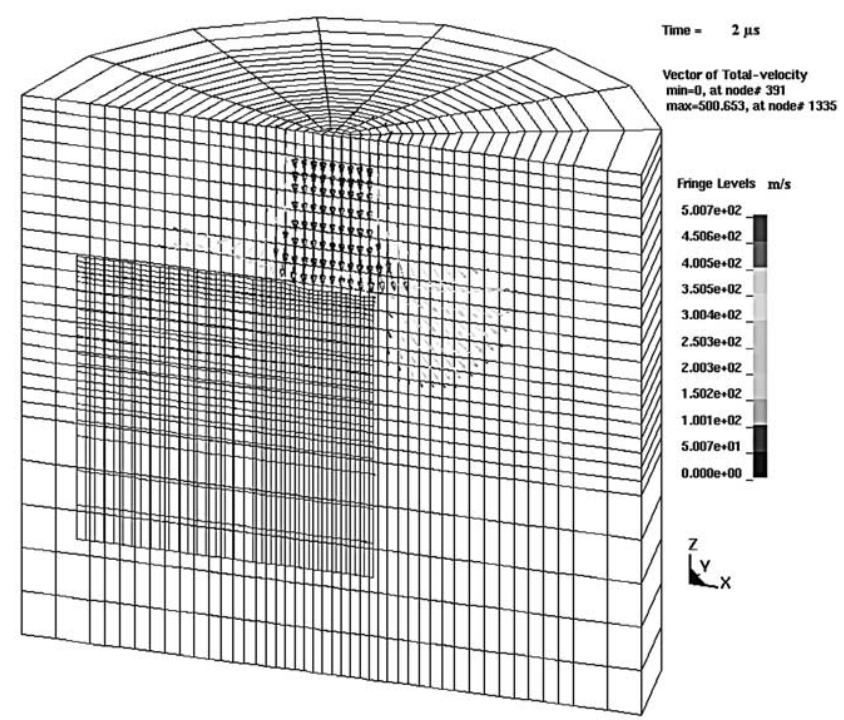

Fig. 6. The beginning of decoating operation (the target moves from left to right).

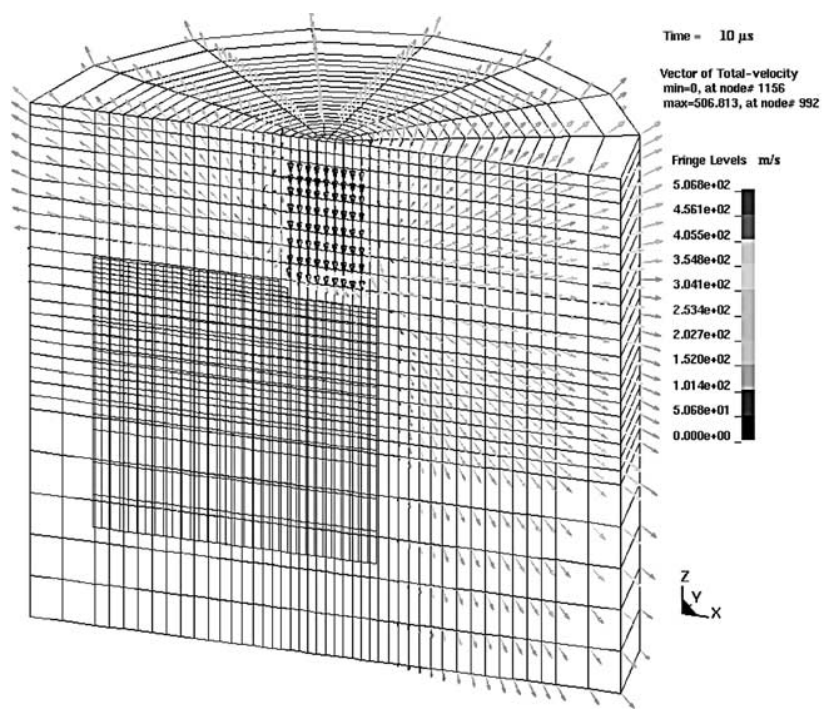

Fig. 7. The decoating operation is established-we observe the erosion phenomenon.

(Figs. 7-9). When the decoating operation is established, the field velocity of water and air has a pronounced value at the jet back region. First blow, it appears that jet flattening seems to be an important parameter influencing the decoating morphology. The achieving of decoating operation is characterised by a jet trajectory modification causing a boundary effects.

We point out that in the case of single impacts, we notice over time the presence of a fluidic zone in stagnation statement on the jet axis $[10,16,17,18]$. In the current case, where the target part and jet have a relative motion, this zone will disappear at steady decoating state.

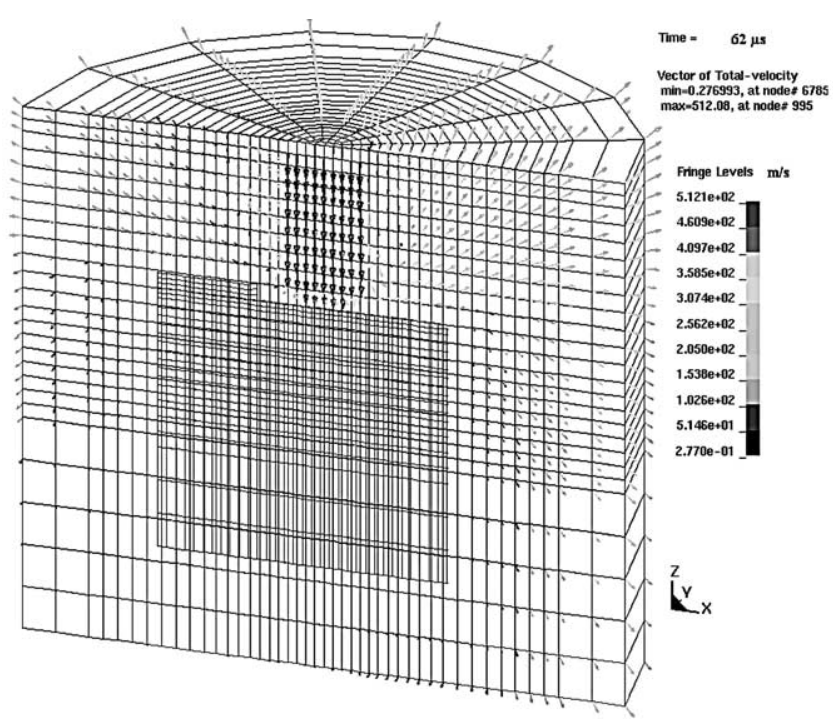

Fig. 8. The field velocity of water and air has pronounced values at the jet back region. 


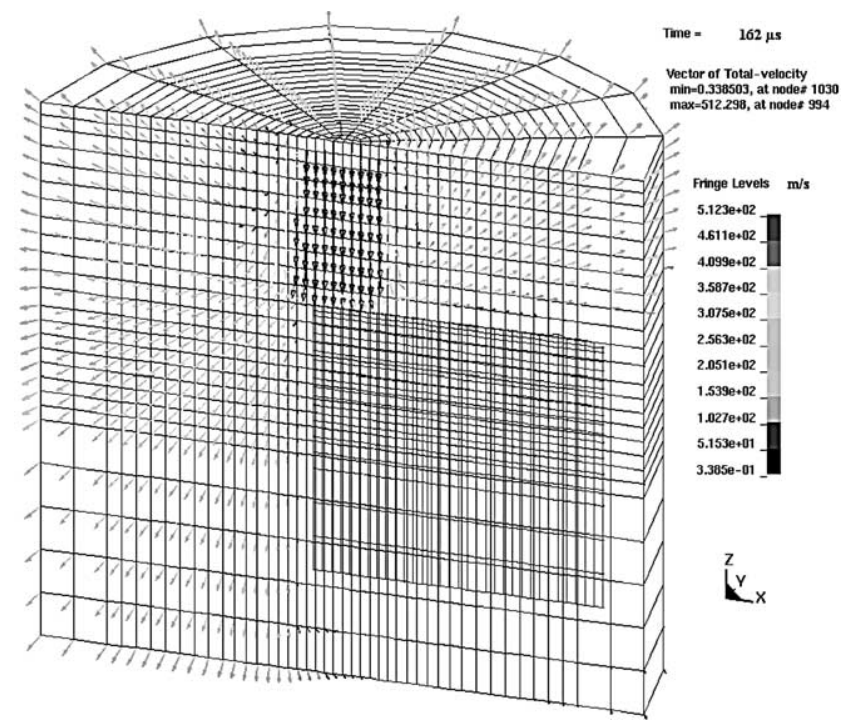

Fig. 9. The end time of decoating operation.

\subsection{Target behaviour during decoating}

In this section, we propose to study the stress field evolution generated during waterjet-target interaction. Some computed quantities are represented in figures corresponding to cross-sections as is shown by figure (Fig. 10).

Fig. 11 represents, for a $2 \mu$ s waterjet exposure time, the (YZ)-stress distribution and the corresponding waterjet velocity field in (A1-A2) cross-section. This stage is characterised by a shear state which has a maximum value localised at the impact zone periphery. It reaches a value of $22.61 \mathrm{MPa}$. No erosion is observed at this time. The morphology of the imprint is characterised by a little hump at the impact center. The latter is surrounded by a ring shaped zone. This morphology does

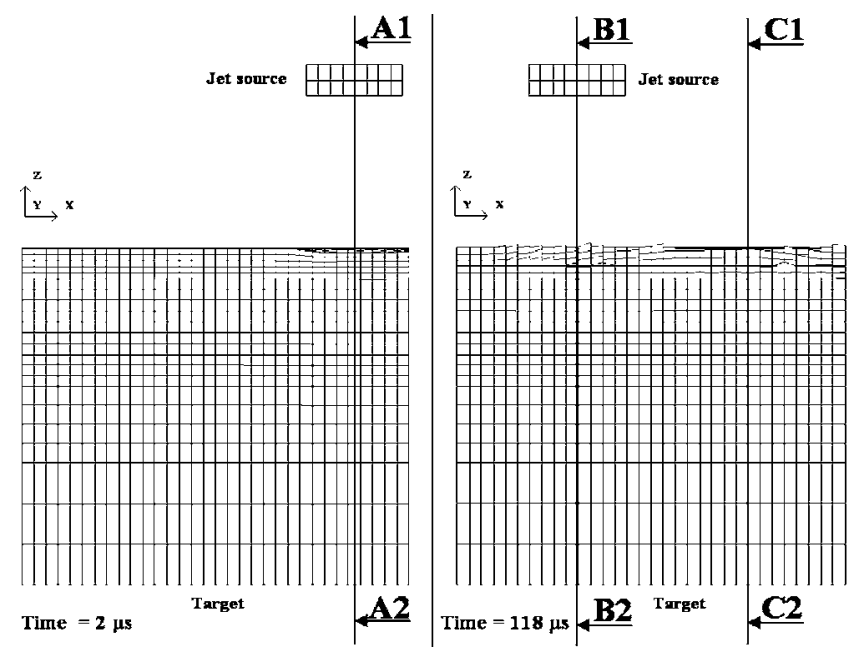

Fig. 10. Plans of cross-section used in representing computed quantities.

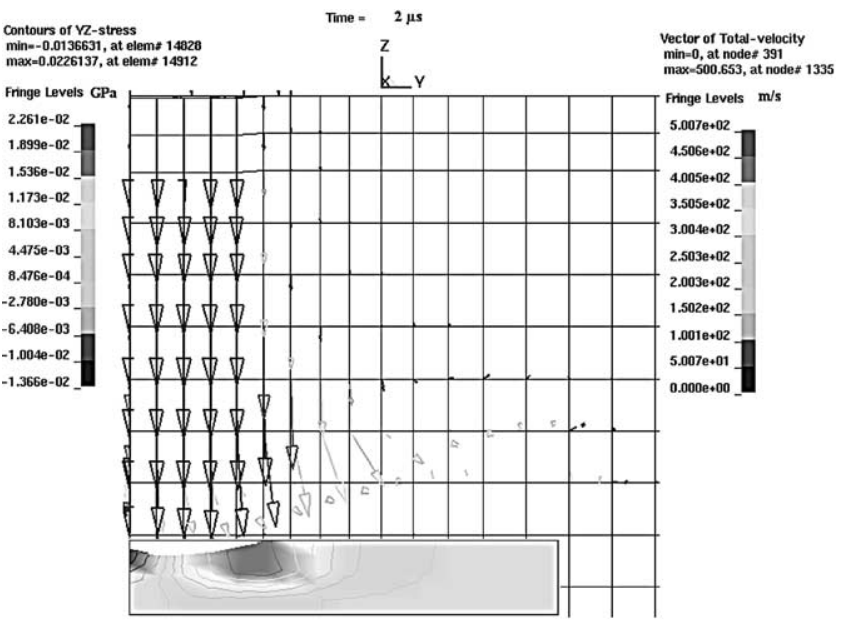

Fig. 11. Distribution of (YZ) stresses and waterjet velocity field viewed in $(\mathrm{A} 1-\mathrm{A} 2)$ cross-section (time $=2 \mu \mathrm{s})$.

not remain during the steady decoating process; it is only a first state of decoating.

For higher exposure times (118 and $174 \mu \mathrm{s})$, the distributions of Von Mises stresses within the treated coating are illustrated by Fig. 12. In the latter, we note that maximum computed stresses are concentrated at the eroded site periphery. This proves that the flattening of the moving waterjet seems to be an important phenomenon influencing the imprint morphology evolution

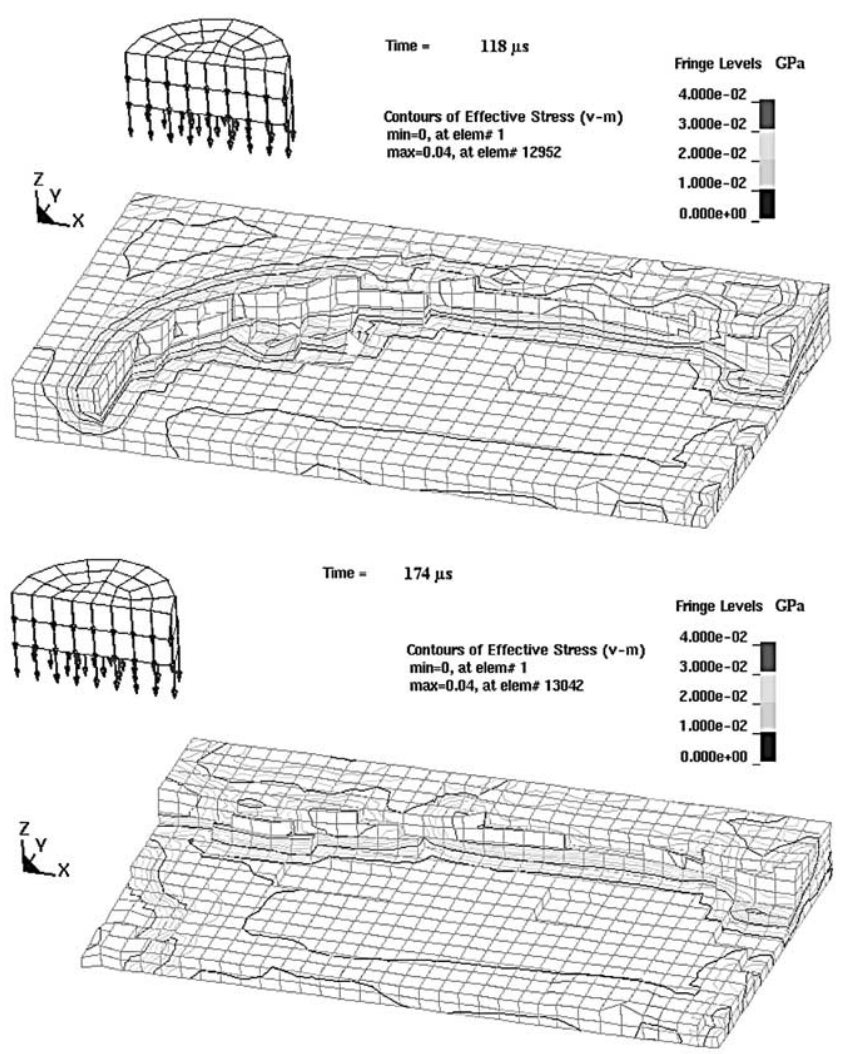

Fig. 12. Distributions of Von Mises stresses within the treated coating. 
(generation of shear stresses on the coating). Moreover, we note a localised stress in the $x$-direction; a zone which corresponds to the central passage of the waterjet. As we will see in Section 5, devoted to experimental results, this site could show discontinuous cracks in the $x x$-direction.

When dealing with the distribution of Von Mises stresses at the upper surface of substrate (A2024) (Fig. 13), we note that the level of residual stresses introduced after the jet passage reaches $166 \mathrm{MPa}$. These stresses have a spoon shaped distribution. The greater the distance covered by the jet the greater the stress concentration located according to $x x$-direction.

The plotting of $z x$-shear stress distribution is shown in Fig. 14, which corresponds, to (C1-C2) cross-section for an exposure time of $118 \mu \mathrm{s}$. According to this figure, the $x x$-axis stresses are higher in the left zone than in the right one. This is due to the fact that the component of the waterjet field velocity in the $(-x)$ axis opposes the target movement ( $+x$ direction). Consequently, there is an increase of the shearing state in this area. On the other hand, in the zone of the right-hand side, the velocity of the target is in the same direction as in that introduced by waterjet flattening.

The $y z$-shear stresses are shown in Fig. 15. When examining this figure, we note that the major values of the stresses, in this half model, are positive. This is explained by the scraping effect introduced by the waterjet when it is in contact with the target.

Fig. 16 shows the various stages of coating erosion until a time of $174 \mu \mathrm{s}$. Indeed, at $2 \mu$ s we notice that the coating undergoes a plastic deformation. After this time, the erosion is initiated. In this case of normal impact, the substrate is not yet reached and the jet

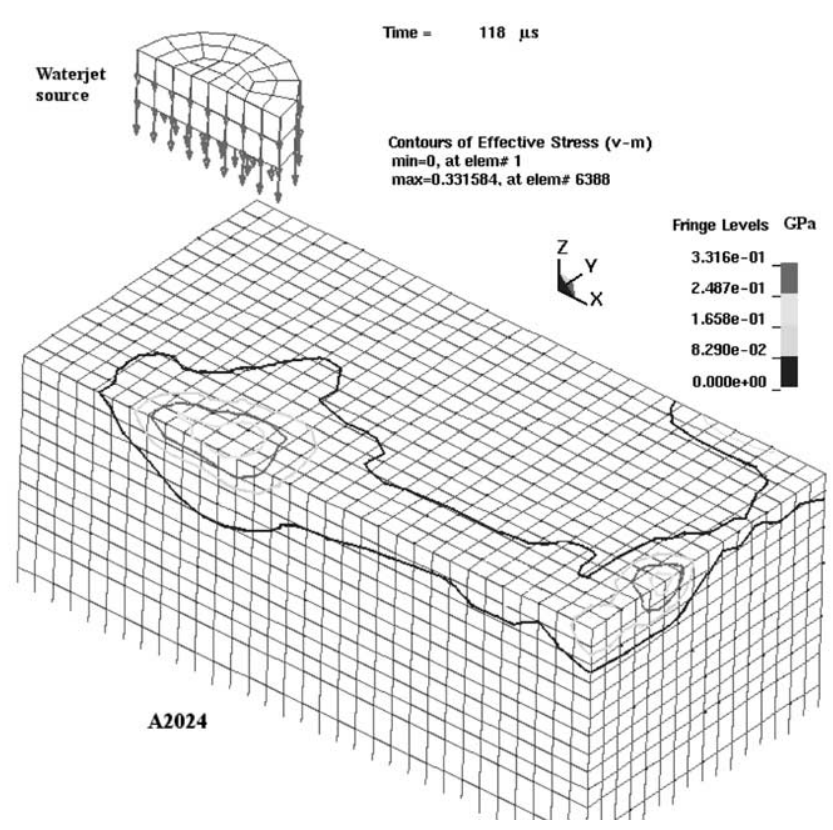

Fig. 13. Distributions of Von Mises stresses within the treated coating.

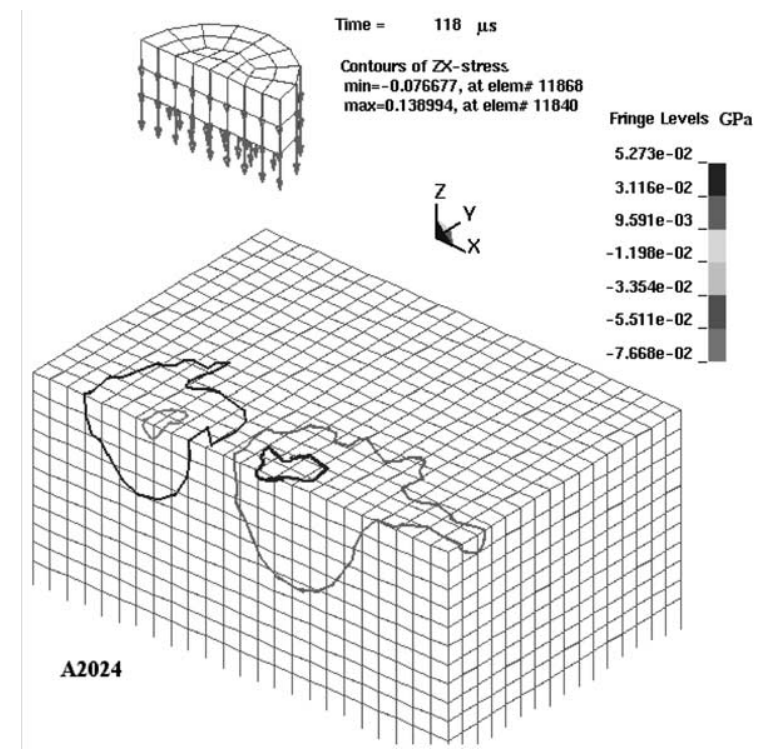

Fig. 14. Distribution of $z x$-stresses within the treated coating (plan C1-C2).

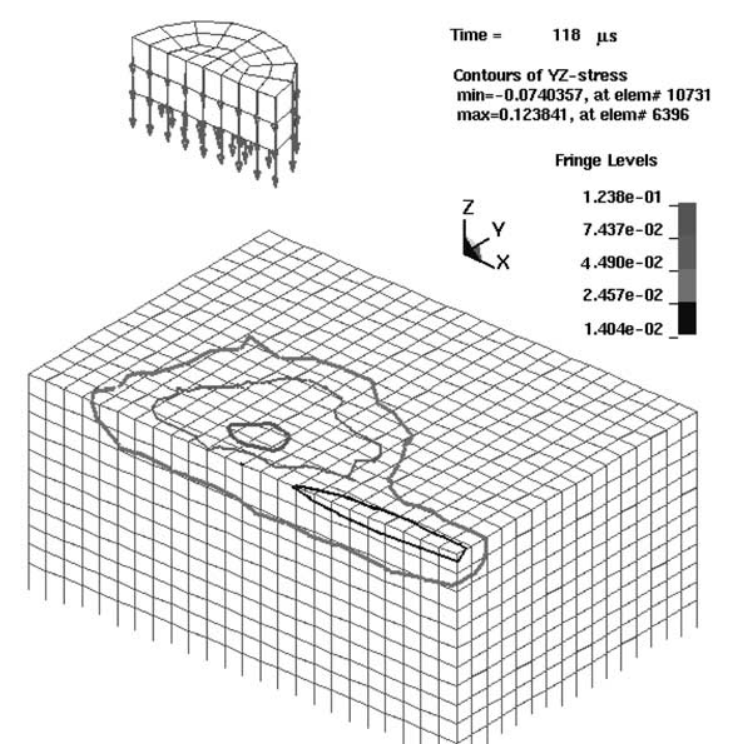

Fig. 15. Distribution of $y z$-stresses within the treated coating (plan C1-C2).

removes a coating layer neighboured to $60 \mu \mathrm{m}$ without attacking the substrate. According to the last result, the action which most favoured this erosion, was the action of scraping produced by the flattening of the waterjet on the target.

Another case, which puts forward the effectiveness of jet action on coating, is the incidence angle of the waterjet (Fig. 17). For that, we have introduced a 15 degree angle of inclination between the jet's central axis and the target. The importance of this parameter is illustrated by Figs 18 and 19. Hydrodynamic results show that upstream of the jet is an accentuated erosion state. It appears that the backside of an inclined jet has an 

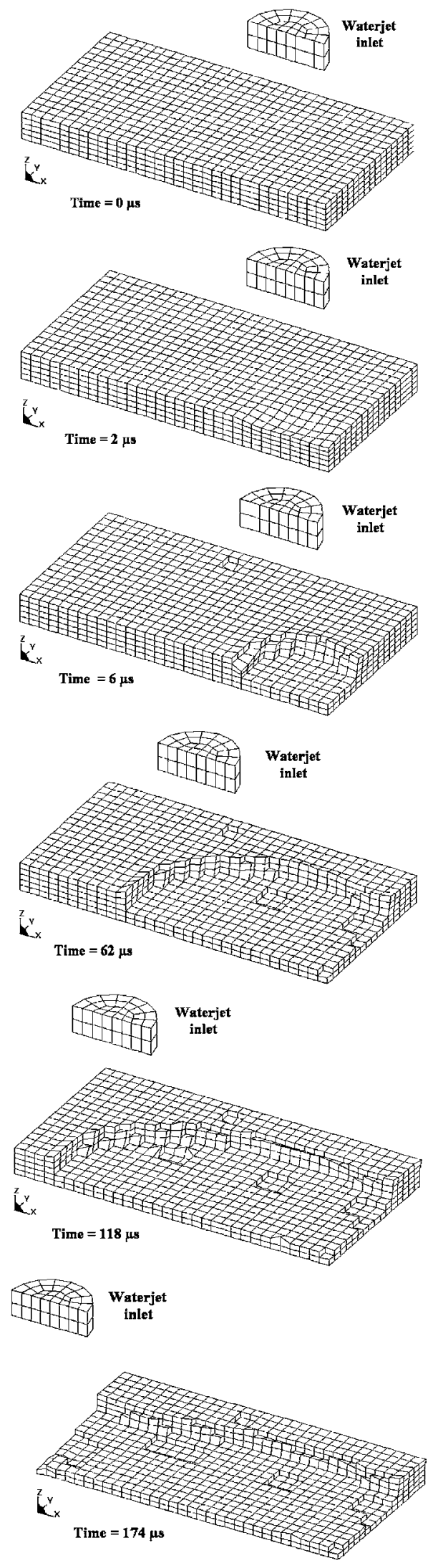

Fig. 16. Simulation of erosion stages — case of stripping by moving mono-jet.

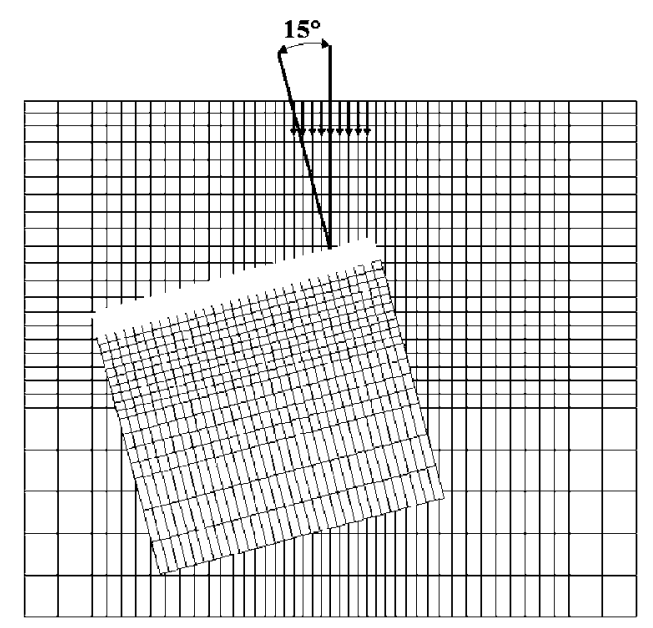

Fig. 17. Inclined waterjet.
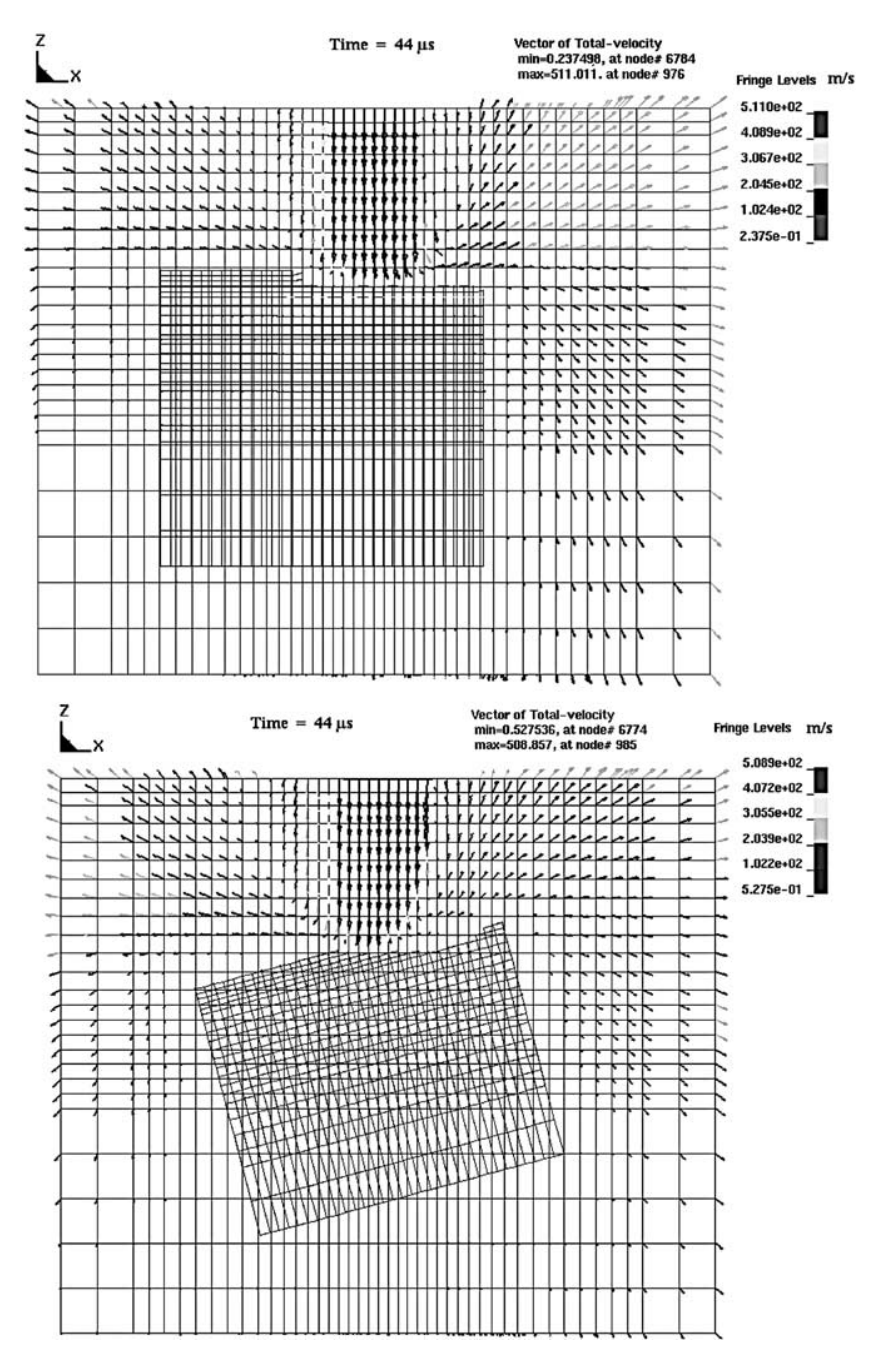

Fig. 18. Comparison of erosion by normal and inclined waterjet, respectively. 

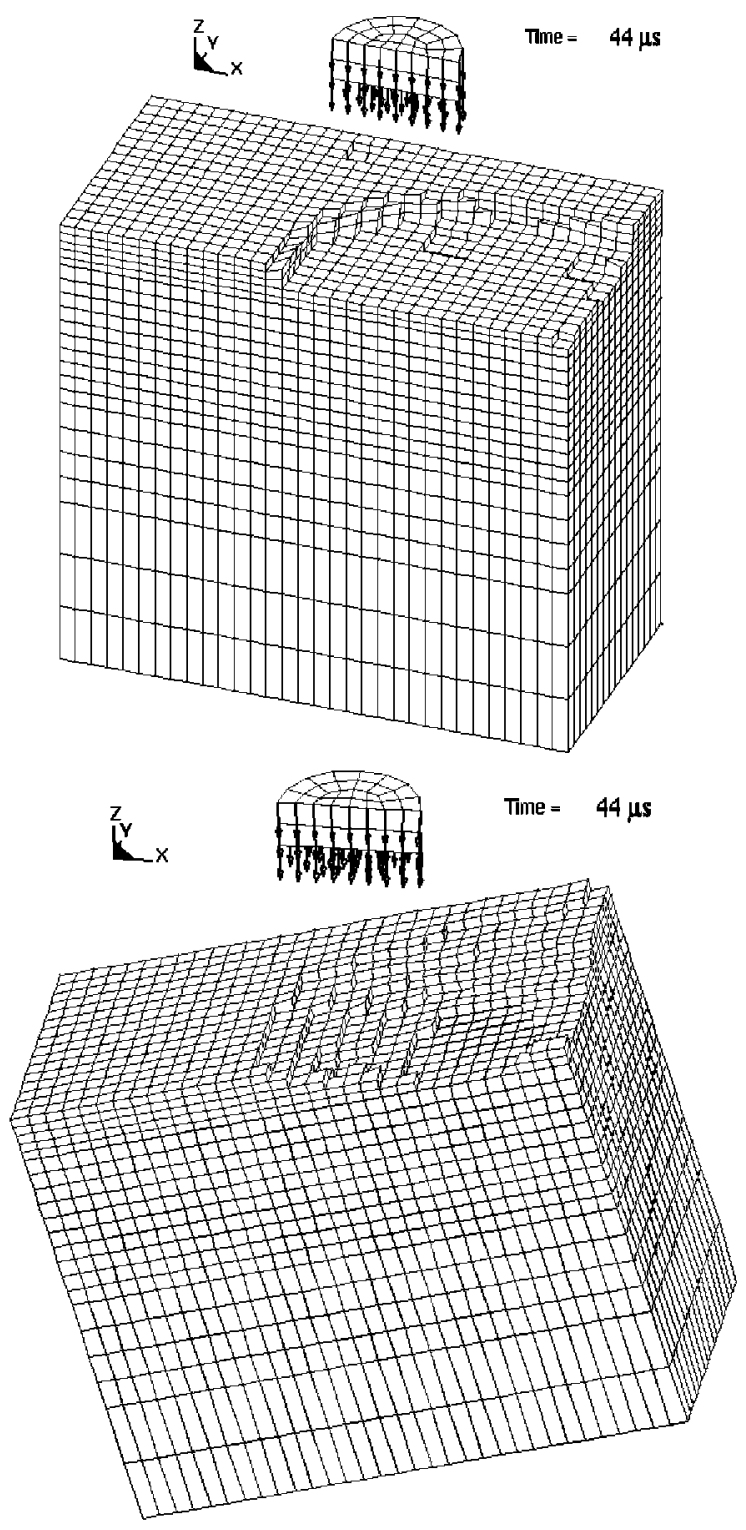

Fig. 19. Influence of waterjet incidence angle on target erosion.

important effect on erosion acceleration. Consequently, the upper surface of the substrate is reached. We point out that according to Rochester [4] the maximum mass loss caused by a waterjet fired against Perspex varies between 15 and 20 degrees of incidence angle.

\section{Experimental results}

In order to study the interaction between the waterjet and coated material, we have performed many experimental tests on different paint types [16-18]. The experimental device used consists of putting two chopper disks (D1, D2) (Fig. 20) on a rotating movement. These disks have an appropriate speed reduction ratio in order to delay the time between two successive crossings of the slots. The control of the jet exposure time is governed
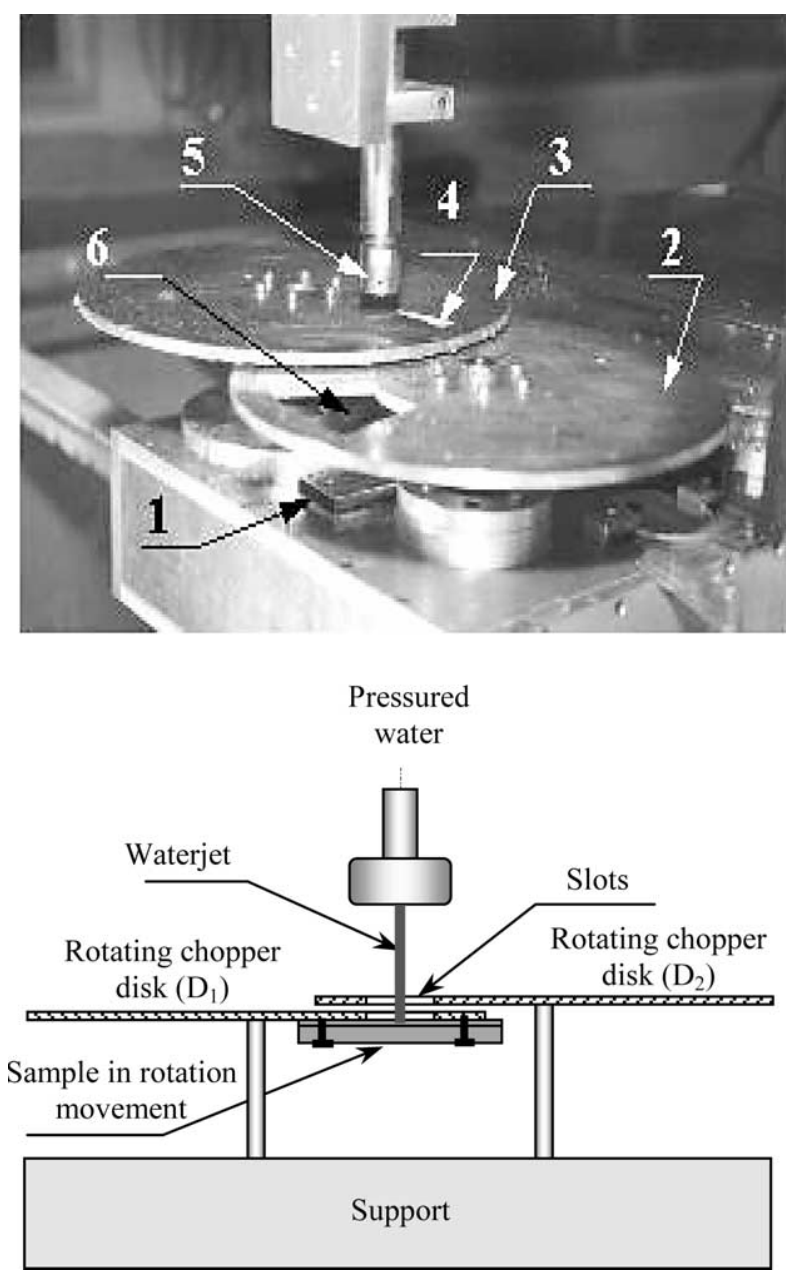

Fig. 20. The control exposure time test-bed used in experiments [specimen (1), rotating chopper disks $(2,3)$, nozzle $(5)$, slots $(4,6)]$.

by the slot length and by the motor speed, which animates the disks in rotation movement [19]. The jet given by the test bed is chopped. The type of such jets was tested by Kaye et al. [4] to explore jet cleaning of thin deposited soils.

The experiments were conducted using a pump, which delivers a pressure up to 4000 bars. The jet is supplied from a constant pressure through a nozzle of $d_{0}=0.3 \mathrm{~mm}$ cross-section diameter. The stand-off distance is fixed at $d_{\text {sod }}=30 \mathrm{~mm}$. Each sample is fixed to the bottom of the chopper disk (D2) (Fig. 20), and is treated by the jet for a controlled exposure time. The latter is governed by the jet passage duration, through the two disk slots. These tests allow us to examine the imprint morphology occurring on the polyurethane coating. In the following, we only present the case of a sample with a $5.7 \mathrm{~m} / \mathrm{s}$, linear velocity. The generated imprint corresponding to this velocity is shown by Fig. 21a. One representation of the imprint groove profile is illustrated by Fig. 21b. In this case the limit width is given by the periphery effectiveness of the jet zone and it is equal to $0.80 \mathrm{~mm}$ with a 
(a)

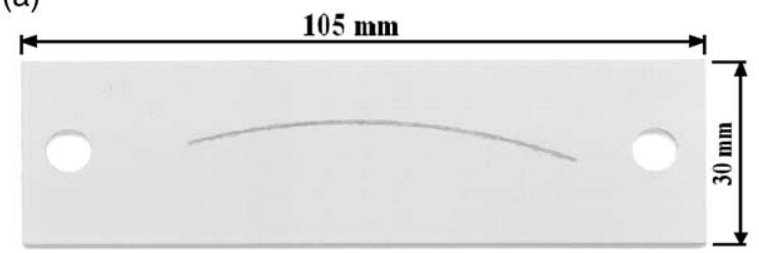

(b)

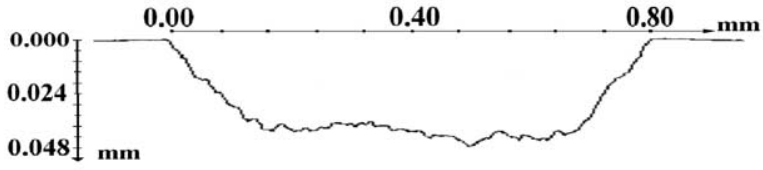

(c)

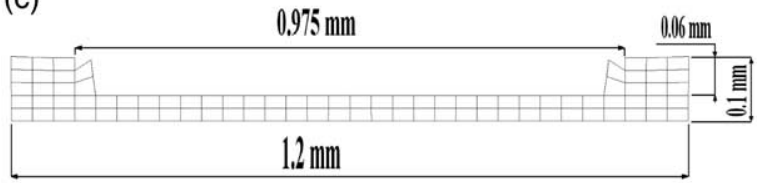

Fig. 21. Imprint morphologies: experimental and numerical results.

maximum depth of $48 \mu \mathrm{m}$. These values are close to those given by the numerical method (Fig. 21c).

In order to understand the coating removal mode, we have performed a microscopic observation on the imprint generated during the waterjet-target interaction (Fig. 22). We have noticed the presence of discontinuous

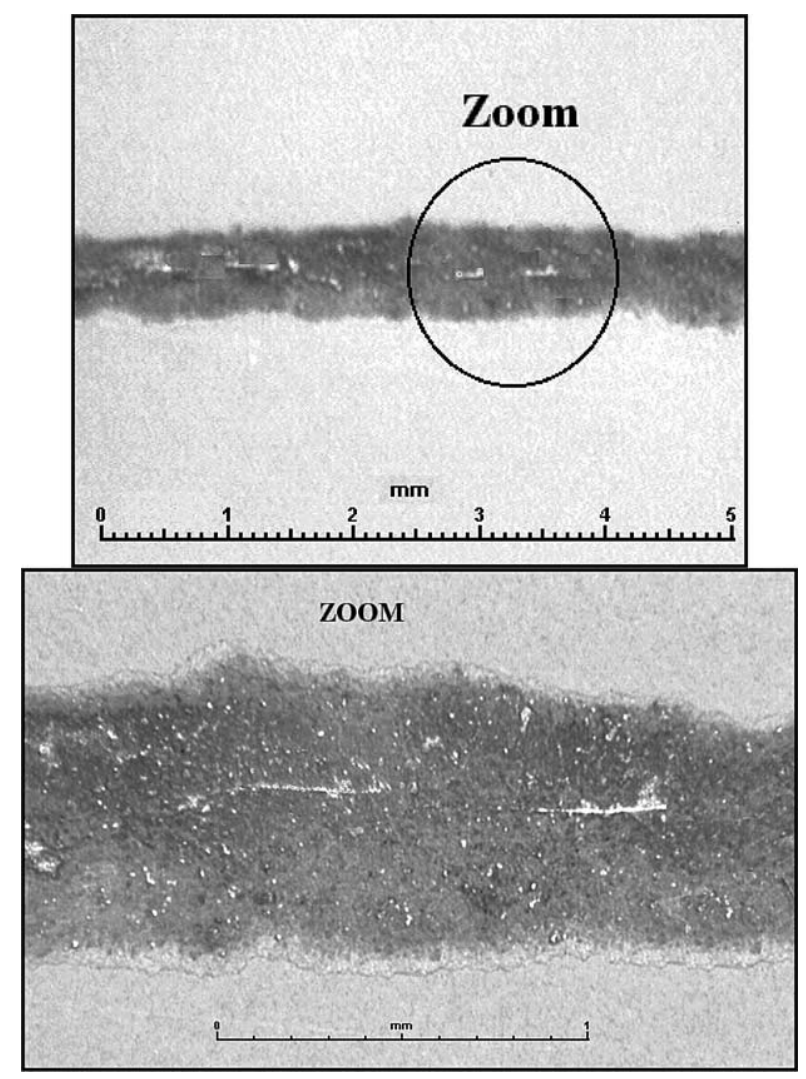

Fig. 22. Microscopic observation waterjet imprint on polyurethane (cracks in median line of imprint). cracks at the median line of the imprint. This behaviour is caused by the opposite stretching generated by jet on target. Numerical results shown by Fig. 15 confirm this behaviour. Consequently, it clearly appears, for this type of coated material, that in addition to the dominating erosion effect of a waterjet, it can produce a crack phenomenon, which participates in the decoating process. Indeed, these cracks can be privileged sites traversed by speedy micro-jets accelerating the coating removal.

\section{Conclusions}

The present work deals with waterjet stripping process simulation using a finite element code (LS-DYNA). The non-overcoming of this process encouraged us to adopt a numerical modelling to understand the interactional physics between a moving waterjet and a coated target. Despite the simplifying assumption adopted, we have numerically shown the importance of the hydrodynamics of the jet on the erosion phenomenon observed during an operation of decoating. We have demonstrated the stress distribution generated during stripping. This makes it possible to understand the material removal mode. A numerical test introducing the modification of the jet incidence (15-degrees) showed the effectiveness of the jet to remove more coating when compared to a normal moving waterjet. Our modelling has been validated by experimental tests, which have shown, in addition to the erosion mode, the possibility of the coating cracking. This is the result of the tearing phenomenon caused by the waterjet action. Consequently, cracks are traversed by speedy micro-jets accelerating the coating removal.

Soon, modelling will be extended to simulate the phenomena existing during the crossing of imprints generated by several moving waterjets. In the aim to develop a predictive numerical simulation, we will perform also a parametric study of the process.

\section{References}

[1] H. Louis, W. Schikorr, Fundamental aspects in cleaning with high speed waterjets, in: Proc 6th Int Conf Jet Cutting Techn, Guildford, 1982, pp. 217-228.

[2] A.F. Conn, Waterjet cleaning for in-factory application, in: Proc 11th Int Conf Jet Cutting Techn, Dordrecht, 1992, pp. 443-449.

[3] S.S. Wu, T.J. Kim, An application study of plain waterjet process for coating removal, in: Proc 8th Int Conf Jet Cutting Techn, Houston, 1995, pp. 779-792.

[4] P.L. Kaye, C.S.J. Pickles, J.E. Field, K.S. Julian, Investigation of erosion process as cleaning mechanism in the removal of thin deposited soils, Wear 186-187 (1995) 413-420.

[5] M.C. Leu, P. Meng, E.S. Geskin, L. Tismeneskiyv, Mathematical modeling and experimental verification of stationary waterjets 
cleaning process, Trans. ASME-J. Manuf. Sci. Engin., August 120 (1998) 571-579.

[6] P. Meng, E.S. Geskin, M.C. Leu, F. Li, L. Tismeneskiy, An analytical and experimental study of cleaning with moving waterjets, Trans. ASME-J. Manuf. Sci. Engin. 120 (1998) 580-589.

[7] H. Louis, W. Milchers, F. Pude, Experimental and theoretical investigation of the decoating process by pure waterjet, in: . 10th American Waterjet Conf., August, 14-17, Houston, Texas, 1999, paper 54.

[8] G.S. Springer, Erosion by Liquid Impact, Scripta Publishing Co., Washington, DC, 1976.

[9] J.O. Hallquist, LS-Dyna3D, Theoretical Manual, Livermore Software Technology, 1997.

[10] T. Mabrouki, K. Raissi, A. Cornier, A numerical simulation and experimental study of the interaction between a pure high-velocity waterjet and targets: contribution to investigate the decoating process, Wear 239 (2000) 260-273.

[11] K. Yanaida, Flow characteristics of water jets, in: Proc. 2nd Int. Symp. Jet Cutting Tech., BHRA Fluid Engng., Cranfield, 1974, p. A2.

[12] K.F. Neusen, T.G. Gores, R.S. Amano, Axial variation of particle and drop velocities downstream from an abrasive water jet mixing tube. in: Jet Cutting Tech Mechan. Engng. Publ. Ltd., London, 1994, pp. 93-103.
[13] R.A. Tikhomirov V, B. Babanini, E.N. Pethukov, High Pressure Jet Cutting, ASME Press, New York, 1992.

[14] LS-Dyna3D Course, Fluid/Structure Coupling (Dynalis-ChE-1910-1998).

[15] D.J. Benson, Momentum advection on a staggered mesh, J. Comput. Phys. 100 (1) (1992)

[16] T. Mabrouki, K. Raissi, A. Cornier, Numerical simulation of high velocity pure waterjet impingement on coated material, in: 15th Int Conf Jetting Tech., Ronneby, Sweden, 6-8, Sept, 2000, pp. 199-217.

[17] T. Mabrouki, A. Cornier, K. Raissi, Experimental investigation and numerical modeling of HP pure waterjet impingement in the aeronautical decoating process, in: 13th Int Conf Surf Treat Aeronautical and Aerospace Industries, Surfair2000, Cannes, 14-16 June, 2000.

[18] T. Mabrouki, Exploration Expérimentale et Modélisation Numérique des Impacts Fluidiques : Contribution à l' Etude du Décapage par Jet d' Eau Pure HP, Thesis, 6 June 2000, ENSAMParis, France.

[19] T. Mabrouki, A. Cornier, K. Raissi, The study of HP pure waterjet impact as the primary mechanism of paint decoating process, in: 14th Int Conf Jetting Techn, Brugge, Belgium, 21-23, Sept., 1998, pp. 563-577. 